\title{
Critical appraisal of axitinib in the treatment of advanced renal cell carcinoma
}

This article was published in the following Dove Press journal:

Biologics:Targets and Therapy

27 February 2013

Number of times this article has been viewed

\author{
Jawaher Ansari' \\ Syed A Hussain² \\ Asif Ansari ${ }^{3}$ \\ John Glaholm ${ }^{4}$ \\ 'Beatson West of Scotland Cancer \\ Centre, Glasgow, UK; ${ }^{2}$ Department \\ of Molecular and Clinical Cancer \\ Medicine, University of Liverpool, \\ Liverpool, UK; ${ }^{3}$ Cleveland Clinic, \\ Cleveland, Ohio, USA; ${ }^{4}$ University \\ Hospital Birmingham NHS Trust, \\ Edgbaston, Birmingham, UK
}

\begin{abstract}
A growing understanding of the biology of renal cell carcinoma (RCC) has led to the development and US Food and Drug Administration approval of seven new molecular targeted agents over the past 7 years. Axitinib is a potent, selective, second-generation inhibitor of vascular endothelial growth factor receptors and the latest to join the armamentarium of drugs available for the treatment of metastatic RCC. Despite recent advances in the development of molecular targeted agents for metastatic RCC, the ideal sequencing of these agents remains unclear.

Keywords: metastatic RCC, vascular endothelial growth factor receptor inhibitor, molecular targeted agent, clear-cell carcinoma
\end{abstract}

\section{Introduction}

Kidney cancer is the fourteenth most common cancer worldwide, with an estimated 273,500 new cases diagnosed in 2008. ${ }^{1}$ Renal cell carcinoma (RCC) accounts for 90\% of all kidney cancers with conventional clear-cell carcinoma being the predominant subtype $(75 \%-80 \%)$.

Interferon- $\alpha$ (IFN- $\alpha$ ) and interleukin-2 (IL-2) treatments have shown poor response rates $(<15 \%)$, with only modest improvement in overall survival (OS). ${ }^{2}$ Treatment with IL-2 has shown prolonged remission (arguably, cure) in a small percentage of patients but is associated with considerable treatment-related morbidity and mortality. Highdose IL-2 has shown durable complete remission in approximately $5 \%$ of patients but has never demonstrated improvement in OS in a randomized controlled trial., ${ }^{2,3}$

A growing understanding of the biology of RCC has led to the development and US Food and Drug Administration (FDA) approval of seven new agents targeting specific growth pathways. Targets for RCC therapy (Figure 1) include Von HippelLindau (VHL)-mediated pathways - vascular endothelial growth factor (VEGF), epidermal growth factor receptor (EGFR), mammalian target of rapamycin (mTOR), platelet-derived growth factor (PDGF) - and non-VHL mediated pathways, such as Raf-kinase, phosphatidylinositol 3-kinase, and Akt. This review aims to summarize the systemic treatment options for first- and second-line treatment of metastatic renal cell carcinoma ( $\mathrm{mRCC}$ ), with a focus on axitinib, the most recent drug to be approved by the FDA for this indication.

\section{Molecular pathogenesis}

Environmental and clinical factors such as smoking, obesity, occupational exposure to toxic compounds (cadmium, asbestos, and petroleum byproducts), and 


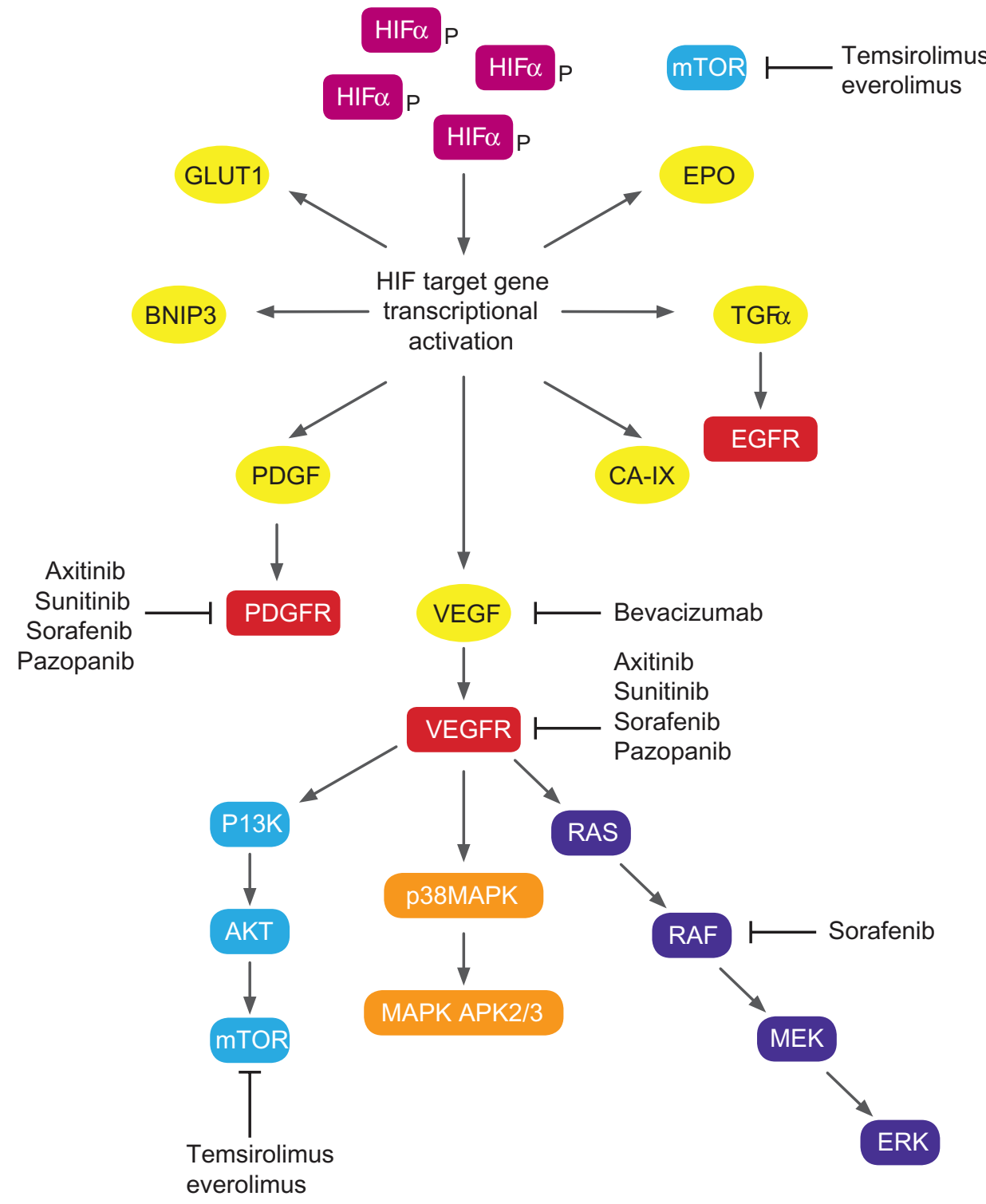

Figure I Biological pathways and targets for molecular targeted agents in renal cell carcinoma.

Abbreviations: APK, activated protein kinase; BNIP3, BCL2/adenovirus EIB I 9 kDa protein-interacting protein 3; CA IX, carbonic anhydrase IX; EGFR, epidermal growth factor receptor; EPO, erythropoietin; ERK, extracellular signal-regulated kinase; GLUTI, glucose transporter I; HIF, hypoxia-inducible factor; MAPK, mitogen-activated protein kinase; MEK, mitogen-activated protein kinase kinase; mTOR, mammalian target of rapamycin; PI3K, phosphatidylinositol 3-kinases; PDGF, platelet-derived growth factor; PDGFR, platelet-derived growth factor receptor; TGF, transforming growth factor; VEGF, vascular endothelial growth factor; VEGFR, vascular endothelial growth factor receptor.

analgesic abuse have been implicated in the etiology of RCC. Several inherited disorders including hereditary papillary renal cancer, VHL disease, and Birt-Hogg-Dubé syndrome predispose to a higher risk of RCC development. VHL disease, an autosomal dominant disorder, is associated with structural abnormalities on chromosome $3 p$ and is characterized by a predisposition to a variety of neoplasms, including RCC. Most patients with primary sporadic clear-cell RCC have either mutations or silencing of the VHL tumor-suppressor gene. ${ }^{4} \mathrm{VHL}$ inactivation simulates hypoxic conditions leading to accumulation of hypoxia-inducible factor (HIF)-1 $\alpha$. HIF-1 $\alpha$ binds to HIF-1 $\beta$, forming a transcriptional factor complex, which translocates to the nucleus and facilitates production of multiple growth factors including VEGF and PDGF. These growth factors subsequently bind to specific tyrosine kinase receptors (vascular endothelial growth factor receptor [VEGFR]-1, VEGFR-2, VEGFR-3, and platelet-derived growth factor receptors [PDGFRs]) resulting in cell migration, endothelial cell growth, and proliferation. mTOR, a serine/threonine-specific kinase is involved in multiple tumor-promoting intracellular signaling pathways in RCC. 
mTOR inhibition also exhibits antiangiogenesis activity by reducing levels of HIF- $1 \alpha$ and VEGF. ${ }^{5}$

\section{Current first-line systemic treatment of $\mathrm{mRCC}$}

Results of the pivotal Phase III clinical trials of molecular targeted agents that are FDA approved for use in the firstline treatment of patients with $\mathrm{mRCC}$ are summarized in Table 1.

\section{Sunitinib}

Sunitinib is an orally available multi-kinase inhibitor with potent activity against VEGFRs (types $1-3), \operatorname{PDGFR}(\alpha, \beta)$, and $\mathrm{c}-\mathrm{Kit}$ oncogene. In a multicenter Phase III randomized controlled trial of 750 treatment-naïve patients with good/ intermediate prognosis $\mathrm{mRCC}$, treatment with sunitinib ( $50 \mathrm{mg}$ daily for 4 weeks followed by a 2-week break) was associated with an improvement in progression-free survival (PFS) (11 vs 5 months; $P<0.001)$ and OS (26.4 vs 21.8 months; $P=0.05$ ) when compared with IFN- $\alpha{ }^{6}$

\section{Pazopanib}

Pazopanib is an oral angiogenesis inhibitor targeting VEGFR, PDGFR, and c-Kit oncogene. The pivotal Phase III randomized double-blind placebo-controlled trial evaluated the efficacy and safety of pazopanib in treatment-naïve and cytokine-pretreated patients $(n=435)$ with advanced RCC. Treatment with pazopanib demonstrated an improved objective response rate (ORR) $(30 \%$ vs $3 \% ; P<0.001)$ and median PFS (9.2 vs 4.2 months; $P<0.0001$ ) when compared to placebo. ${ }^{7}$

\section{Temsirolimus}

Temsirolimus is a parenterally administered rapamycin analog that functions as a competitive inhibitor of mTOR kinase. Temsirolimus was evaluated in a Phase III trial in which 626 previously untreated poor-prognosis patients with metastatic or recurrent RCC were randomly assigned to temsirolimus (25 mg intravenously/week), temsirolimus (15 mg intravenously/week) plus IFN- $\alpha$ (escalated up to 6 million units three times/week as tolerated), or IFN- $\alpha$ monotherapy (escalated up to 18 million units three times/ week as tolerated). Temsirolimus significantly prolonged the median PFS (3.1 vs 5.5 months) and median OS (7.3 vs 10.9 months; hazard ratio [HR] $0.73,95 \%$ confidence interval [CI] $0.58-0.92 ; P=0.008)$ when compared with singleagent IFN- $\alpha{ }^{8}$

\section{Bevacizumab}

Bevacizumab is a monoclonal antibody that binds circulating VEGF and prevents its interaction with VEGFR. Two similarly designed Phase III trials have demonstrated improved PFS with bevacizumab plus IFN- $\alpha$ compared with IFN- $\alpha$ alone. In the avastin and roferon for renal cell carcinoma (AVOREN) trial, 649 treatment-naïve $\mathrm{mRCC}$ patients were randomized to IFN- $\alpha$ ( 9 million units three times/week) plus either bevacizumab (10 mg/kg every 2 weeks) or placebo. Median PFS was significantly improved in the bevacizumab plus IFN- $\alpha$ arm in comparison to the control group (10.2 vs 5.4 months; HR $0.63,95 \%$ CI $0.52-0.75 ; P=0.0001) .{ }^{9}$ Final analysis showed a median OS of 23.3 months with bevacizumab plus IFN- $\alpha$ and 21.3 months with IFN- $\alpha$ plus placebo (HR 0.91, 95\% CI 0.76-1.10; $P=0.3360) .{ }^{10}$ In the Cancer and Leukemia Group B (CALGB) trial 90206, 732

Table I Summary of Phase III clinical trial results for targeted agents approved for first-line treatment of metastatic renal cell carcinoma

\begin{tabular}{|c|c|c|c|c|c|c|c|c|}
\hline References & Indication & $\mathbf{n}$ & Drugs & $\begin{array}{l}\text { OR (CR + PR) } \\
(\%)\end{array}$ & $\begin{array}{l}\text { Median PFS } \\
\text { (months) }\end{array}$ & $P$ value & $\begin{array}{l}\text { Median OS } \\
\text { (months) }\end{array}$ & $P$ value \\
\hline \multirow[t]{2}{*}{ Motzer et al ${ }^{6}$} & Treatment naïve & 750 & Sunitinib & 47 & 11 & $<0.001$ & 26.4 & 0.051 \\
\hline & & & IFN- $\alpha$ & 12 & 5 & & 21.8 & \\
\hline \multirow[t]{2}{*}{ Sternberg et $\mathrm{al}^{7}$} & Treatment naïve and & 435 & Pazopanib & 30 & 9.2 & $<0.0001$ & NR & \\
\hline & cytokine pretreated & & Placebo & 3 & 4.2 & & & \\
\hline \multirow[t]{2}{*}{ Escudier et al ${ }^{9}$} & Treatment naïve & 649 & Bevacizumab + IFN- $\alpha$ & 31 & 10.4 & 0.0001 & 23.3 & 0.3360 \\
\hline & & & IFN- $\alpha$ & 12 & 5.5 & & 21.3 & \\
\hline \multirow[t]{2}{*}{ Rini et al" } & Treatment naïve & 732 & Bevacizumab + IFN- $\alpha$ & 25.5 & 8.5 & $<0.0001$ & 18.3 & 0.097 \\
\hline & & & IFN- $\alpha$ & 13.1 & 5.2 & & 17.4 & \\
\hline \multirow[t]{3}{*}{ Hudes et al ${ }^{8}$} & Treatment naïve & 626 & Temsirolimus ( 25 mg/wk) & 8.6 & 5.5 & & 10.9 & \\
\hline & & & $\begin{array}{l}\text { Temsirolimus (15 mg/wk) + } \\
\text { IFN- } \alpha\end{array}$ & 8.1 & 4.7 & & 8.4 & \\
\hline & & & IFN- $\alpha$ & 4.8 & 3.1 & & 7.3 & \\
\hline
\end{tabular}

Abbreviations: CR, complete response; IFN, interferon; OR, objective response; OS, overall survival; PFS, progression-free survival; PR, partial response. 
treatment-naïve patients with $\mathrm{mRCC}$ were randomly assigned to IFN- $\alpha$ plus bevacizumab or IFN- $\alpha$ plus placebo on schedules similar to those used in the AVOREN trial. There was a statistically significant increase in the ORR (25.5 vs 13.1 percent) and median PFS (8.5 vs 5.2 months; HR 0.71, 95\% CI $0.61-0.83$ ) for the bevacizumab plus IFN- $\alpha$ arm. ${ }^{11}$ The final analysis of this trial revealed a trend toward improved median OS (18.3 vs 17.4 months; HR $0.86 ; P=0.07$ ) for the bevacizumab plus IFN- $\alpha$ arm. ${ }^{12}$

\section{Second-line clinical trials Sorafenib}

Sorafenib is a potent small molecule multi-kinase inhibitor of VEGFR-2, fms-like tyrosine kinase receptor-3, PDGFR, and fibroblast growth factor receptor-1. In the Phase III Treatment Approaches in Renal Cancer Global Evaluation Trial (TARGET), in which 903 patients with advanced RCC who had failed prior standard therapy (IFN- $\alpha$ or IL-2) were randomly assigned to sorafenib (400 mg orally twice daily) or placebo. There was a significant prolongation of median PFS in the sorafenib $\operatorname{arm}(5.5$ vs 2.8 months; HR 0.44, 95\% CI 0.35-0.55) but no significant difference in the median OS between the two arms (17.8 vs 15.2 months; HR 0.88, 95\% CI 0.74-1.04). ${ }^{13}$

\section{Everolimus}

Everolimus is an orally administered selective inhibitor of mTOR, a key serine-threonine kinase that plays an essential role in downstream protein synthesis of the PI3K/AKT pathway; is dysregulated in many human cancers; and is an essential component of an intracellular signaling pathway regulating cell growth and proliferation, metabolism, and angiogenesis. Everolimus is a derivative of rapamycin and has been in clinical development since 1996 as an immunosuppressant in solid organ transplantation. The encouraging Phase II clinical trial results in RCC led to the development of the pivotal Phase III clinical trial, RECORD-1.

This trial, a Phase III randomized study, assessed the efficacy of everolimus in patients with mRCC and disease progression on or within 6 months of stopping treatment with sunitinib or sorafenib, or both. A total of 410 patients were randomized in a 2:1 ratio to receive everolimus (10 mg daily) or placebo. The trial was terminated early by the Independent Data Monitoring Committee as an interim analysis demonstrated a significant difference in PFS between the two arms (4.9 vs 1.9 months with everolimus and placebo, respectively; $P<0.001)$. The improvement in PFS extended to all stratification sets irrespective of risk group, prior treatment status, age, or sex. No complete responses were observed; the partial response rate was $1.8 \%(n=5)$ with everolimus and $0 \%$ with placebo. Although Response Evaluation Criteria In Solid Tumors-defined objective responses were rare $(<2 \%)$ with everolimus, any reduction in tumor measurement from baseline as best percentage change was observed in $47 \%$ of patients treated with everolimus versus $10 \%$ with placebo. Stable disease by independent central review was noted in 185 (66.8\%) of 277 patients in the everolimus arm versus 45 (32.4\%) of 139 in the placebo arm. Based on these results, everolimus has been recommended as a second-line treatment option for metastatic clear-cell RCC patients who have failed first-line VEGFR-tyrosine kinase inhibitor (TKI) treatment. ${ }^{14}$

The median OS was 14.8 months for the everolimus arm versus 14.4 months for the placebo arm (HR 0.87; $P=0.162$ ). The lack of significant difference in survival could be explained by the degree of crossover after the un-blinding of the trial following interim analysis; $76 \%$ of patients in the placebo arm had crossed over to everolimus. ${ }^{15}$ Preplanned, prospective subgroup analysis compared the efficacy of everolimus in patients who received one previous VEGFRTKI treatment to those who received two or more $(26 \%){ }^{16}$ Of the patients who had received one previous VEGFR-TKI treatment, median PFS was 5.4 months with everolimus and 1.9 months with placebo (HR $0.32,95 \%$ CI: $0.24-0.43$; $P<0.001)$. Of the patients who had received two previous VEGFR-TKI treatments, the median PFS was 4.0 months with everolimus and 1.8 months with placebo (HR 0.32 , 95\% CI $0.19-0.54 ; P<0.001)$. The authors concluded that everolimus was associated with prolonged PFS relative to placebo in patients who received one or two previous VEGFR-TKI treatments. Patients who had received only one previous VEGFR-TKI treatment had apparently longer PFS with everolimus in comparison with those who had received two previous VEGFR-TKI treatments.

\section{Axitinib}

Axitinib (Inlyta ${ }^{\circledR}$, Pfizer, New York, NY, USA; AG-013736) (Figure 2) is a potent, selective, second-generation inhibitor of VEGFR-1, -2, and -3; PDGF; and colony stimulating factor-1 receptor tyrosine kinases. ${ }^{17,18}$ Axitinib is 50-450 times more potent than the first-generation VEGFR inhibitors. Based on pharmacokinetic/pharmacodynamic analysis, axitinib appears to be a selective VEGFR-TKI according to current clinical exposure. ${ }^{19}$

\section{Phase I clinical trials}

A Phase I study by Rugo et al investigated the efficacy, safety, and pharmacokinetics of axitinib in advanced cancer. ${ }^{20}$ 


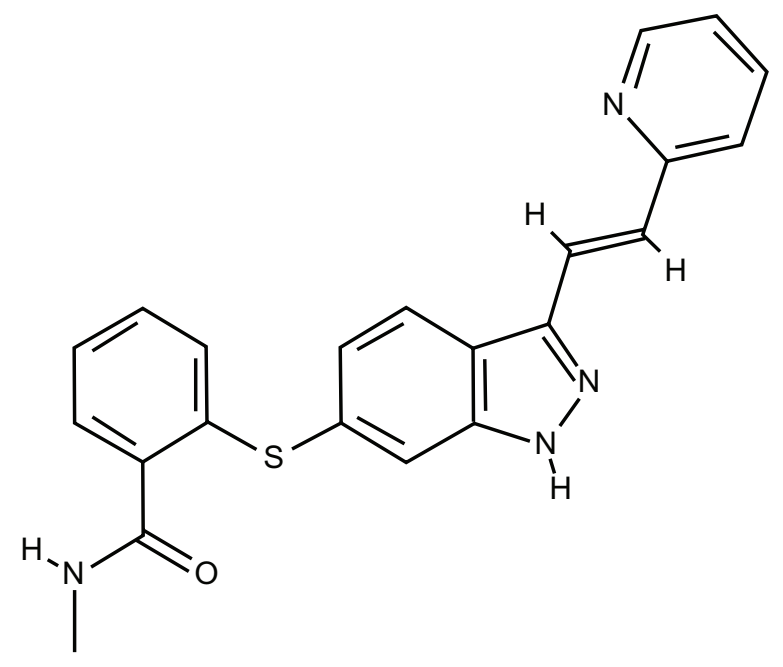

Figure 2 Chemical structure of axitinib.

Thirty-six patients received axitinib at doses between 5 and $30 \mathrm{mg}$ twice daily. Dose-limiting toxicities included hypertension, hemoptysis, and stomatitis. Axitinib was absorbed rapidly, with plasma peak concentrations noted within 2-6 hours of dosing and steady plasma pharmacokinetic state within 15 days. Three confirmed partial responses were noted. This study recommended the maximum-tolerated dose and recommended Phase II dose of axitinib to be $5 \mathrm{mg}$ twice daily.

\section{Phase II clinical trials}

A Phase II multicenter study by Rini et $\mathrm{al}^{21}$ investigated the efficacy and safety of axitinib in patients with sorafenibrefractory metastatic RCC. The starting dose of axitinib was $5 \mathrm{mg}$ twice daily and dose escalation was possible in $53.2 \%$ of patients. Of the 62 patients, overall response rate was $22.6 \%$, with a median duration of response of 17.5 months. The median PFS was 7.4 months (95\% CI 6.7-11.0) and the median OS was 13.6 months (95\% CI 8.4-18.8 months). The most common grade $3 / 4$ adverse events included hand-foot syndrome (16.1\%), fatigue (16.1\%), hypertension (16.1\%), dyspnea (14.5\%), and diarrhea (14.5\%). Post-hoc analysis of this study by Dutcher et al revealed an ORR of $7.1 \%$ for patients with prior treatment with sunitinib and sorafenib, $27.6 \%$ for patients with prior cytokines and sorafenib, and $25 \%$ for prior treatment with sorafenib alone..$^{22}$

In a Phase II study by Rixe et al, 52 patients with $\mathrm{mRCC}$ who had failed at least one cytokine-based treatment were treated with axitinib $5 \mathrm{mg}$ twice daily. ${ }^{23}$ The primary endpoint was objective response (complete plus partial response) and secondary endpoints included duration of response, time to progression (TTP), OS, and patient-reported health-related quality of life. ${ }^{24}$ Results demonstrated an ORR of $44.2 \%$ (95\% CI 30.5-58.7), with a median response duration of 23.0 months (20.9-not estimable; range 4.2-29.8). Median TTP was 15.7 months (95\% CI 8.4-23.4) and the median OS was 29.9 months ( $95 \%$ CI $20.3-$ not estimable). The updated 5-year survival rate was $20.6 \%$ (95\% CI 10.9-32.4). ${ }^{22}$ The most common treatment-related grade $3 / 4$ toxicities included fatigue (21.2\%), diarrhea (19.2\%), and hypertension $(15.4 \%)$.

The results of these Phase II trials (Table 2) suggested that axitinib could be an effective second-line treatment in patients with advanced RCC and led to the development of the pivotal Phase III trial.

\section{Phase III clinical trial}

Axitinib versus sorafenib in advanced renal cell carcinoma (AXIS), a multicenter Phase III randomized controlled trial, which compared axitinib to sorafenib in patients with $\mathrm{mRCC}$ who had progressed despite first-line therapy containing sunitinib, bevacizumab plus IFN- $\alpha$, temsirolimus, or cytokines. ${ }^{25} \mathrm{~A}$ total of 723 patients with metastatic clear-cell RCC were randomized $1: 1$ to either axitinib (5 mg twice daily) or sorafenib (400 $\mathrm{mg}$ twice daily). Dose increments of axitinib to $7 \mathrm{mg}$ and then to $10 \mathrm{mg}$ were allowed for patients without hypertension or adverse reactions above grade 2 . The median duration of treatment was 6.4 months (range $0.03-22$ ) in the axitinib arm and 5.0 months (range $0.03-20$ ) in the sorafenib arm. The median PFS was 6.7 months (95\% CI 6.3-8.6) for axitinib versus 4.7 months (95\% CI 4.6-5.6) for sorafenib (HR $0.665,95 \%$ CI $0.544-0.812$; $P<0.0001$ ). In cytokinepretreated patients, the median PFS was 12.1 months for axitinib versus 6.5 months for sorafenib (HR $0.464,95 \%$ CI 0.318-0.676; $P<0.0001)$. In sunitinib-pretreated patients, the median PFS was 4.8 months for axitinib and 3.4 months for sorafenib (HR 0.741, 95\% CI 0.573-0.958; $P=0.0107$ ). In the overall patient population and the two main subgroups (prior sunitinib treatment and prior cytokine treatment), there was a statistically significant advantage for axitinib over sorafenib for the primary endpoint of PFS.

The median OS was 20.1 months (95\% CI 16.7-23.4) for axitinib versus 19.2 months (95\% CI 17.5-22.3) for sorafenib. In the sunitinib-pretreated patients, the median OS was 15.2 months (95\% CI 12.8-18.3) in the axitinib arm and 7.7 months (95\% CI 4.4-12.4) in the sorafenib arm. In the cytokine-pretreated patients, the median OS was 29.4 months ( $95 \%$ CI 24.5 -not reached) in the axitinib arm and 27.8 months (95\% CI 23.1-34.5) in the sorafenib arm. There were no statistically significant differences between 
Table 2 Summary of second-line Phase II clinical trials of Axitinib in metastatic renal cell carcinoma

\begin{tabular}{|c|c|c|c|c|c|c|}
\hline References & $\begin{array}{l}\text { Previous } \\
\text { treatments }\end{array}$ & Drugs & $\mathbf{n}$ & OR (\%) & $\begin{array}{l}\text { Median PFS } \\
\text { (months) }\end{array}$ & $\begin{array}{l}\text { OS } \\
\text { (months) }\end{array}$ \\
\hline Rini et $\mathrm{al}^{22}$ & Sorafenib & Axitinib $5 \mathrm{mg}$ bd & 62 & 22.6 & $7.4(95 \% \mathrm{Cl} 6.7-\mathrm{II})$ & $\begin{array}{l}\text { I } 3.6(95 \% \\
\text { Cl } 8.4-18.8)\end{array}$ \\
\hline $\begin{array}{l}\text { Rixe et } \mathrm{al}^{23} \text { and } \\
\text { Motzer et } \mathrm{a}^{24}\end{array}$ & Cytokines & Axitinib $5 \mathrm{mg}$ bd & 52 & 44.2 & I 5.7 (95\% Cl 8.4-23.4) & $\begin{array}{l}29.9 \text { (95\% } \\
\mathrm{Cl} 20.3-\mathrm{NR})\end{array}$ \\
\hline
\end{tabular}

Abbreviations: $\mathrm{Cl}$, confidence interval; NR, not reached; OR, objective response; OS, overall survival; PFS, progression-free survival.

the arms in terms of OS in the overall population or in the subgroups by prior therapy.

The ORR assessed by blinded independent radiology review was $19.4 \%$ for axitinib and $9.4 \%$ for sorafenib $(P=0.0001)$. The objective response to axitinib in the sunitinib-pretreated patients was $11.3 \%(95 \%$ CI $7.2-16.7)$ and in the cytokine-pretreated patients was 32.5\% (95\% CI 24.5-41.5). The median duration of response was 11 months (95\% CI 7.4-not reached) for axitinib and 10.6 months for sorafenib (8.8-11.5). The open-label trial design and the potential for dose escalation in the axitinib arm have been criticized. However, it is still unclear if there is any additional benefit of axitinib dose escalation and this is the subject of an ongoing Phase II trial. ${ }^{26}$

Secondary end points of the trial included kidney-specific symptoms, function assessments, and heath-related quality of life. The composite end point of time to deterioration using patient questionnaires (Functional Assessment of Cancer Therapy - Kidney Cancer Symposium Index [FKSI-15]) demonstrated a statistically significant advantage for axitinib when compared with sorafenib (HR 0.829, 95\% CI 0.707-0.993; $P=0.020) .{ }^{27}$ The authors concluded that treatment with axitinib led to a statistically significant improvement in PFS along with a delay in worsening of composite time-to-deterioration end points when compared with sorafenib in treatment-refractory RCC.

\section{Discussion}

Axitinib is a potent and selective VEGFR-TKI, which has demonstrated significant antitumor activity in patients with mRCC. Data from the pivotal AXIS trial makes a compelling case for its use as second-line treatment following failure of previous IFN- $\alpha$ or TKI therapy. ${ }^{25}$ Based on the results of this trial, the FDA (January 2012) and European Medicines Agency (September 2012) approved the use of axitinib for the treatment of advanced RCC after failure of one prior systemic therapy. AXIS is the first trial to have demonstrated the superiority of one targeted agent over another in $\mathrm{mRCC}$ in the second-line setting following failure of one prior systemic therapy. The efficacy of axitinib versus sorafenib in the first-line setting is being investigated in a Phase III trial of patients with $\mathrm{mRCC}$ who are either treatment naïve or have progressed after one therapy. ${ }^{28}$ Results from the TARGET trial are unlikely to influence management in the current era, as the standard first-line treatment on the trial was either IFN- $\alpha$ or IL-2. Results from the nexavar versus torisel as second-line therapy for advanced renal cell carcinoma (INTORSECT) trial, which compared the efficacy of temsirolimus versus sorafenib as second-line treatment in patients with $\mathrm{mRCC}$ were recently presented at the Thirty-Seventh Congress of the European Society of Medical Oncology in October 2012. ${ }^{29}$ Results from this trial showed no significant difference in median PFS (4.28 vs 3.91 months) or OS (12.27 vs 16.64 months) for patients treated with temsirolimus and sorafenib, respectively.

The drug choice in the second-line setting remains unclear, as results from the RECORD-1, AXIS, and INTORSECT trials leave many questions unanswered. In the AXIS trial, the improvement in median PFS was less pronounced in patients receiving first-line sunitinib (4.8 vs 3.4 months; HR 0.741; $P=0.010)$ when compared with patients receiving first-line cytokines (12.1 vs 6.5 months; HR 0.464; $P<0.0001$ ). In the real-world scenario, the post-cytokine cohort is dwindling rapidly, as targeted agents are becoming increasingly available worldwide, either as standard treatment or as part of clinical trials. RECORD-1 and AXIS are two very different clinical trials and it would be difficult to directly compare outcomes.

The rapidity of drug development in this setting makes it difficult to choose the ideal comparator for randomized clinical trials for patients with mRCC. The ideal comparator for the AXIS trial would have been everolimus, but it was not FDA approved until May 2009. Both everolimus and axitinib have demonstrated significant benefit in patients with $\mathrm{mRCC}$ who have progressed after at least one line of systemic therapy, albeit in a different patient population. Patients in the AXIS trial had only failed first-line therapy whereas nearly $80 \%$ of patients in the RECORD-1 trial were heavily pretreated. In addition to VEGFR inhibitors, patients in the everolimus arm were previously treated with immunotherapy (65\%), 
chemotherapy (13\%), and hormonal therapy (2\%). The ideal sequencing of axitinib and everolimus following failure of one TKI remains a challenge and perhaps could only be addressed by a randomized Phase III trial.

\section{Conclusion}

The FDA has approved seven new drugs over the past 7 years, heralding the unprecedented drug development now being undertaken for the management of RCC. Axitinib is the most recent drug to have received FDA approval and is indicated for the treatment of advanced RCC after failure of one prior systemic therapy. Although the AXIS trial met its primary end point of improved PFS, the magnitude of median PFS improvement was more pronounced in the prior cytokinetreatment group when compared with the prior sunitinibtreatment group. There were no statistically significant differences between the treatment arms in terms of OS in the overall population or in the subgroups by prior therapy. Indirect comparisons between the efficacy of everolimus and axitinib are unlikely to be helpful, given the differences in the trial populations. Both everolimus and axitinib are potent drugs in this patient population and the ideal sequencing of drugs in the second-line setting can only be determined by a head-to-head comparison between these agents.

\section{Disclosure}

The authors declare no conflicts of interest in this work.

\section{References}

1. Ferlay J, Shin HR, Bray F, Forman D, Mathers C, Parkin DM. Estimates of worldwide burden of cancer in 2008: GLOBOCAN 2008. Int J Cancer. 2010;127(12):2893-2917.

2. Wirth MP. Immunotherapy for metastatic renal cell carcinoma. Urol Clin North Am. 1993;20(2):283-295.

3. Fyfe G, Fisher RI, Rosenberg SA, Sznol M, Parkinson DR, Louie AC. Results of treatment of 255 patients with metastatic renal cell carcinoma who received high-dose recombinant interleukin-2 therapy. J Clin Oncol. 1995;13(3):688-696.

4. Clifford SC, Prowse AH, Affara NA, Buys CH, Maher ER. Inactivation of the von Hippel-Lindau (VHL) tumour suppressor gene and allelic losses at chromosome arm $3 p$ in primary renal cell carcinoma: evidence for a VHL-independent pathway in clear cell renal tumourigenesis. Genes Chromosomes Cancer. 1998;22(3):200-209.

5. Land SC, Tee AR. Hypoxia-inducible factor 1alpha is regulated by the mammalian target of rapamycin (mTOR) via an mTOR signaling motif. J Biol Chem. 2007;282(28):20534-20543.

6. Motzer RJ, Hutson TE, Tomczak P, et al. Overall survival and updated results for sunitinib compared with interferon alfa in patients with metastatic renal cell carcinoma. J Clin Oncol. 2009;27(22): 3584-3590

7. Sternberg CN, Davis ID, Mardiak J, et al. Pazopanib in locally advanced or metastatic renal cell carcinoma: results of a randomized phase III trial. J Clin Oncol. 2010;28(6):1061-1068.

8. Hudes G, Carducci M, Tomczak P, et al; Global ARCC Trial. Temsirolimus, interferon alfa, or both for advanced renal-cell carcinoma. N Engl J Med. 2007;356(22):2271-2281.
9. Escudier B, Pluzanska A, Koralewski P, et al; AVOREN Trial investigators. Bevacizumab plus interferon alfa-2a for treatment of metastatic renal cell carcinoma: a randomised, double-blind phase III trial. Lancet. 2007;370(9605):2103-2111.

10. Escudier B, Bellmunt J, Négrier S, et al. Phase III trial of bevacizumab plus interferon alfa-2a in patients with metastatic renal cell carcinoma (AVOREN): final analysis of overall survival. J Clin Oncol. 2010; 28(13):2144-2150.

11. Rini BI, Halabi S, Rosenberg JE, et al. Bevacizumab plus interferon alfa compared with interferon alfa monotherapy in patients with metastatic renal cell carcinoma: CALGB 90206. J Clin Oncol. 2008;26(33): $5422-5428$.

12. Rini BI, Halabi S, Rosenberg JE, et al. Phase III trial of bevacizumab plus interferon alfa versus interferon alfa monotherapy in patients with metastatic renal cell carcinoma: final results of CALGB 90206. J Clin Oncol. 2010;28(13):2137-2143.

13. Escudier B, Eisen T, Stadler WM, et al. Sorafenib for treatment of renal cell carcinoma: Final efficacy and safety results of the phase III treatment approaches in renal cancer global evaluation trial. J Clin Oncol. 2009;27(20):3312-3318.

14. Motzer RJ, Escudier B, Oudard S, et al; RECORD-1 Study Group. Efficacy of everolimus in advanced renal cell carcinoma: a double-blind, randomised, placebo-controlled phase III trial. Lancet. 2008;372(9637): 449-456.

15. Motzer RJ, Escudier B, Oudard S, et al; RECORD-1 Study Group. Phase 3 trial of everolimus for metastatic renal cell carcinoma: final results and analysis of prognostic factors. Cancer. 2010;116(18):4256-4265.

16. Calvo E, Escudier B, Motzer RJ, et al. Everolimus in metastatic renal cell carcinoma: Subgroup analysis of patients with 1 or 2 previous vascular endothelial growth factor receptor-tyrosine kinase inhibitor therapies enrolled in the phase III RECORD-1 study. Eur J Cancer. 2012;48(3):333-339.

17. Choueiri TK. Axitinib, a novel anti-angiogenic drug with promising activity in various solid tumors. Curr Opin Investig Drugs. 2008;9(6) 658-671.

18. Kelly RJ, Rixe O. Axitinib - a selective inhibitor of the vascular endothelial growth factor (VEGF) receptor. Target Oncol. 2009;4(4): 297-305.

19. Hu-Lowe DD, Zou HY, Grazzini ML, et al. Nonclinical antiangiogenesis and antitumor activities of axitinib (AG-013736), an oral, potent, and selective inhibitor of vascular endothelial growth factor receptor tyrosine kinases 1, 2, 3. Clin Cancer Res. 2008;14(22):7272-7283.

20. Rugo HS, Herbst RS, Liu G, et al. Phase I trial of the oral antiangiogenesis agent AG-013736 in patients with advanced solid tumors: pharmacokinetic and clinical results. J Clin Oncol. 2005;23(24):5474-5483.

21. Rini B et al. Phase 2 study of Axitinib in sorafenib-refractory metastatic renal cell carcinoma. J Clin Oncol. 2009;27:4462-4468.

22. Dutcher JP, Wilding GR, Hudes WM, et al. Sequential axitinib (AG-013736) therapy of patients (pts) with metastatic clear cell renal cell cancer (RCC) refractory to sunitinib and sorafenib, cytokines and sorafenib, or sorafenib alone. J Clin Oncol. 2008;26(Suppl):Abstr 5127.

23. Rixe O, Bukowski RM, Michaelson MD, et al. Axitinib treatment in patients with cytokine-refractory metastatic renal-cell cancer: a phase II study. Lancet Oncol. 2007;8(11):975-984.

24. Motzer RJ, de La Motte Rouge T, Harzstark AL, et al. Axitinib secondline therapy for metastatic renal cell carcinoma (mRCC): five-year (yr) overall survival (OS) data from a phase II trial. J Clin Oncol. 2011;29(Suppl):Abstr 4547.

25. Rini BI, Escudier B, Tomczak P, et al. Comparative effectiveness of axitinib versus sorafenib in advanced renal cell carcinoma (AXIS): a randomised phase 3 trial. Lancet. 2011;378(9807):1931-1939.

26. Pfizer. Axitinib (AG-013736) with or without dose titration (increase) in patients with kidney cancer. In: ClinicalTrials.gov [website on the Internet]. Bethseda, MD: US National Library of Medicine; 2009 [updated November 9, 2012]. Available from: http://clinicaltrials.gov/ ct2/show/NCT00835978. NLM identifier: NCT00835978. Accessed November 23, 2012. 
27. Cella D, Escudier B, Rini BI, et al. Patient-reported outcomes (PROs) in a phase III AXIS trial of axitinib versus sorafenib as second-line therapy for metastatic renal cell carcinoma (mRCC). J Clin Oncol. 2011;29(Suppl):Abstr 4504.

28. Pfizer. Axitinib (AG-013736) for the treatment of metastatic renal cell cancer. In: ClinicalTrials.gov [website on the Internet]. Bethseda, MD: US National Library of Medicine; 2009 [updated November 19, 2012]. Available from: http://clinicaltrials.gov/ct2/show/NCT00920816. NLM identifier: NCT00920816. Accessed November 23, 2012.
29. Hutson T, Escudier B, Esteban E, et al. Temsirolimus vs Sorafenib as Second Line Therapy in Metastatic Renal Cell Carcinoma: Results From the INTORSECT Trial. Presented at the 37th Congress of the European Society for Medical Oncology (ESMO), Vienna, Austria, September 28-October 2, 2012. Abstract LBA22.

\section{Publish your work in this journal}

Biologics: Targets \& Therapy is an international, peer-reviewed journal focusing on the patho-physiological rationale for and clinical application of Biologic agents in the management of autoimmune diseases, cancers or other pathologies where a molecular target can be identified. This journal is indexed on PubMed Central, CAS, EMBase, Scopus

\section{Dovepress}

and the Elsevier Bibliographic databases. The manuscript management system is completely online and includes a very quick and fair peerreview system, which is all easy to use. Visit http://www.dovepress com/testimonials.php to read real quotes from published authors. 